CENDEKIA, Vol. 11, No. 1, April 2017

p ISSN: 1978 2098; e -ISSN: 2407 8557

Http://cendekia.pusatbahasa.or.id; Email: cendekiaoslo@gmail.com

Center of Language and Culture Studies, Surakarta, Indonesia

Muhsan. 2017. Jargon dalam Interaksi Sosial Bahasa Sasak oleh Siswa MAN Lombok Barat. Cendekia, (2017), 11(1): 51 64.

\title{
JARGON DALAM INTERAKSI SOSIAL BAHASA SASAK OLEH SISWA MAN LOMBOK BARAT
}

\author{
Muhsan \\ Magister Pendidikan Bahasa Indonesia \\ Universitas Mataram \\ Jl. Majapahit No. 62 Mataram \\ E-mail: muhsantebao3@gmail.com
}

\begin{abstract}
This research described the use of jargon in social interaction of Sasak language. The researcher evoked the issue on forms, function and meaning of jargon used by students of MAN Gerung, West Lombok regency. This research is a descriptive research that used qualitative approach. The techniques of data collection were observation and documentation. The data were analyzed through specific linguistic feature based on linguistic attitude. The results were summarized as follows: 1) forms of jargon were found in terms of word and phrase forms, 2) the functions of jargon were for communicative simplicity, identiying function and milieu restoration. While the meaning of the data jargon jargon MAN Gerung students varies based on the students' understanding.
\end{abstract}

Keywords: Jargon, Social interaction, Sasak Language.

Bahasa memiliki fungsi-fungsi tertentu dalam pergaulan di antara sesama anggota sesuai dengan kelompok (Aslinda dan Leni Syafyahya, 2007:2). Dalam Khomariah, (2011:3). Dalam kehidupan sosial, selalu ada kelompok tertentu yang mempunyai bahasa tertentu yang merupakan lambang identitas kelompoknya, yang ditandai dengan kekhasan prilaku dan pemakain bahasa. Kekhasan inilah yang membedakan dari kelompok lain. Kekhasan ini hanya dipahami oleh mereka dalam kegiatan yang mereka lakukan bersama, perbedaan bahasa yang satu dengan yang lain dalam sebuah masyarakat tutur diakibatkan karena keheterogenan penuturnya.

Variasi bahasa yang kerap kali dijumpai pada suatu kelompok tertentu, kadang disebut sebagai bahasa suatu kelompok. Bahasa kelompok dalam suatu komunitas sering diistilahkan sebagai jargon, argot, atau slang. Menurut kamus Larouse jargon adalah kosa kata khusus yang digunakan oleh kalangan tertentu berdasarkan profesi atau kelas sosial. Jargon bisa juga berarti bahasa yang digunakan oleh para pelaku tindak kriminal dan pengguna obat-obat terlarang agar mereka bisa berkomunikasi secara bebas tanpa dipahami oleh orang-orang di luar kelompok, supaya kelompok tersebut dapat merahasiakan topik pembicaraan mereka. Penggunaan jargon biasanya dikelompokkan menurut profesi atau kelas-kelas sosialnya. 
CENDEKIA, Vol. 11, No. 1, April 2017

p ISSN: 1978 2098; e ISSN: 2407 8557

Http://cendekia.pusatbahasa.or.id; Email: cendekiaoslo@gmail.com

Center of Language and Culture Studies, Surakarta, Indonesia

Muhsan. 2017. Jargon dalam Interaksi Sosial Bahasa Sasak oleh Siswa MAN Lombok Barat. Cendekia, (2017), 11(1): 51 64.

Jargon dalam sebuah kelas sosial biasanya digunakan untuk merahasiakan suatu topik pembicaraan. Oleh karena itu jargon sering digunakan dengan cara membolakbalik suku katanya, memberikan perumpamaan dengan suatu benda yang menyerupai ataupun tidak sama sekali ( hanya sebagai simbol dari suatu benda). Sehingga orang lain diluar kelompok tersebut tidak dapat memahami pembicaraan. Beberapa jargon yang digunakan dalam sebuah kelompok sosial merupakan kata-kata yang terdapat dalam kamus, tetapi layaknya bahasa-bahasa percakapan masyarakat Inggris dan Amerika atau bahasa percakapan masyarakat Jakarta, jargon sudah menjadi bagian dari bahasa seharihari.

Berdasarkan uraian di atas, penelitian ini mengangkat permasalahan pemakaian bahasa jargon yang digunakan oleh siswa Madrasah Aliah Negeri Gerung. Siswa di Madrasah Aliyah Negeri Gerung ini memiliki latar belakang yang berbeda-beda bahkan berasal dari daerah yang berbeda seperti Lombok Barat, Lombok tengah, Lombok timur, dan Kota Mataram. Siswa yang bersifat heterogen ini menimbulkan pemakaian bahasa yang khas dikalangan mereka sehingga peneliti sangat tertarik untuk mengangkat isu pemakaian jargon di kalangan siswa Madrasah Aliyah Negeri Gerung. Dalam penelitian ini, peneliti akan membahas secara khusus tentang bentuk, fungsi dan makna jargon yang dipakai dalam berkomunikasi oleh siswa Madrasah Aliyah Negeri Gerung.

Bahasa terdiri dari dua aspek yang mendasar, yaitu aspek bentuk dan makna. Aspek bentuk berkaitan dengan bunyi, tulisan, dan struktur, sedangkan makna bersifat leksikal dan fungsional. Bahasa dalam aspek bentuk dan makna seringkali menunjukkan perbedaan kecil maupun besar. Perbedaan-perbedaan dalam bahasa akan menghasilkan ragam dan variasi bahasa.

Variasi bahasa merupakan pokok bahasan dalam studi sosiolinguistik, sehingga Kridalaksana (1974, dalam Chaer dan Agustina 2004:61) mendefinisikan sosiolinguistik sebagai cabang linguistik yang menjelaskan ciri-ciri variasi bahasa dan menetapkan korelasi ciri-ciri bahasa tersebut dengan ciri-ciri sosial kemasyarakatan. Menurut Soeparno dalam Dasar-dasar Linguistik (2003:55-61) mengemukakan bahwa variasi bahasa terdiri dari variasi kronologisvariasi geografis variasi sosial variasi fungsional variasi gaya/style variasi kultural dan variasi individual.

Jargon merupakan bagian dari variasi bahasa dalam sebuah kelompok masyarakat. Di dalam sebuah masyarakat sosial, baik menurut profesi, kelas sosial maupun umur, mempunyai tendensi untuk menciptakan sebuah bahasa, yang kemudian menjadi bahasa jargon dalam suatu kelompok tertentu. Para pengamat menandai bahwa munculnya banyak kosa kata khusus jargon anak muda di kalangan anak muda sekarang, yang berhubungan dengan jargon, kata-kata spesifik dan simpul kata (Gak, 1986:135). Dalam kelompok-kelompok orang yang berbicara dialek gegrafis dan sosial yang sama ini terdapat variasi-variasi bahasa yang tergantung dari situasi-situasi khusus.

Orang-orang yang mempunyai kegiatan atau profesi yang sama inilah yang membedakan mereka dari orang-orang yang tergolong dalam kelompok sosial di luar mereka. Para remaja, pencuri, dan tuna susila memiliki satu jargon yang membedakan 
CENDEKIA, Vol. 11, No. 1, April 2017

p ISSN: 1978 2098; e ISSN: 2407 8557

Http://cendekia.pusatbahasa.or.id; Email: cendekiaoslo@gmail.com

Center of Language and Culture Studies, Surakarta, Indonesia

Muhsan. 2017. Jargon dalam Interaksi Sosial Bahasa Sasak oleh Siswa MAN Lombok Barat. Cendekia, (2017), 11(1): 51 64.

mereka dari orang tua dan masyarakat (Mokienko, dan Nikitina, 2005:3). Tidak dapat dipungkiri bahwa jargon banyak digunakan dalam percakapan sehari-hari di setiap bidang kehidupan. Meluasnya pemakaian jargon dikarenakan semakin bertambahnya populasi dalam komunitas, sehingga menyebabkan terjadi westernasi, perbedaan tingkat sosial, ataupun profesinya. Jargon tidak hanya digunakan dalam percakapan sehari-hari, tetapi juga digunakan dalam karya-karya sastra, novel, majalah, dan lain-lain.

Dari defenisi di atas dapat disimpulkan bahwa jargon adalah bagian dari variasi bahasa dalam sebuah kelompok masyarakat, baik menurut profesi, kelas sosial, maupun umur. Kelompok sosial dalam masyarakat mempunyai tendensi untuk menciptakan sebuah bahasa, yang kemudian menjadi bahasa jargon dalam suatu kelompok tertentu. Jargon juga sangat bersinggungan lansung dengan kehidupan sosial masyarakat. Hal ini terlihat dari penggunaan jargon dalam karya sastra, bidang jurnalistik kehidupan sosial, dan linguistik. Adapun bentuk jargon tersebut adalah:

\section{Bentuk Kata}

Kata adalah satuan bahasa yang memiliki satu pengertian atau deretan huruf yang diapit oleh dua buah spasi, dan mempunyai satu arti (Chaer, 2003:162). Bentuk jargon yang berupa kata merupakan wujud yang tidak mengalami perubahan bentuk, yang digunakan secara apa adanya, untuk mengungkapkan perasaan dan pikiran seseorang.

\section{Bentuk frasa}

Frasa adalah gabungan kata yang bersifat non predikatif, atau lazim juga disebut gabungan kata yang mengisi salah satu fungsi sintaksis didalam kalimat (Chaer, 2003:222). Misalnya, gunung tinggi, disebut frasa karena merupakan konstruksi nonpredikat.

\section{Bentuk Non Verbal}

Penggunaan bahasa jargon yang berupa non verbal dalam bahasa tulis merupakan suatu bentuk kata yang tidak berupa kata, hanya berupa simbol atau lambang. Bentuk simbol atau lambang merupakan suatu ungkapan. Bentuk simbol dapat berupa exspresi jiwa seseorang yang memerlukan pengetahuan dan imajinasi yang kuat untu menafsirkannya.

Cristiana (2008), menyatakan ada beberapa tipe jargon yang umum dikenal masyarakat yaitu Legalese, Corporate speak, dan tecnical terms. Menurut Wikipedia (2014), Legalese is the style of English used by lawyers and other legal professionals in the course of their work. Dalam kamus Encarta, legalese didefiisikan "language that is typically used in legal documents and is generally considered by lay people to be difficult to understand".

Dari kedua definisi diatas, dapat disimpulkan bahwa legalese adalah bahasa yang digunakan oleh kelompok pekerja profesional dalam bidangnya misalnya pengacara atau yang berhubungan dengan hukum dan sulit dimengerti oleh orang lain. Jadi, 
CENDEKIA, Vol. 11, No. 1, April 2017

p ISSN: 1978 2098; e ISSN: 2407 8557

Http://cendekia.pusatbahasa.or.id; Email: cendekiaoslo@gmail.com

Center of Language and Culture Studies, Surakarta, Indonesia

Muhsan. 2017. Jargon dalam Interaksi Sosial Bahasa Sasak oleh Siswa MAN Lombok Barat. Cendekia, (2017), 11(1): 51 64.

legalese merupakan gaya bahasa yang menggunakan kosakata tehnis dalam permasalahan hukum.

Corporate speak juga dikenal dengan sebutan corporate jargon. Wikipedia (2014) mendefinisikan corporate speak sebagai "the jargon often used in large corporations, bureaucracies, and similar workplaces". Dari definisi di atas dapat diartikan bahwa jargon yang sering digunakan dalam perusahan besar sulit dimengerti oleh kelompok lain, misalnya birokrasi, bank dan lain sebagainya. Dalam komunikasi, Jargon memiliki tiga fungsi yaitu sebagai berikut;

a. Fungsi dalam penggunaanya yaitu fungsi yang memudahkan bagi orang atau kelompok yang memahaminya, mempermudah pengungkapan keterangan yang panjang dan berbelit sehingga menjadi bahasa yang efektif dan efisien dalam komunitas tersebut.

b. Fungsi sebagai identitas kelompok tertentu. Kemampuan dalam menggunakan jargon akan mempengaruhi kreadibilitas dan kelayakan seseorang dalam kelompok karena mampu memahami ide dasar dalam kelompok tesebut. Selain itu jargon juga dapat meningkatkan image, citra, dan prestige, oleh karena itu seseorang yang sering menggunakan jargon sesuai dengan kelompok yang diikutinya atau tempat bekerja yang di geluti seseorang tersebut akan semakin bangga dengan register yang digunakannya.

c. Selain itu, Jargon juga berfungsi untuk mengakrabkan dan menyegarkan suasana komunikasi atau interaksi dengan sesama kelompok-kelompok tertentu.

Penggunaan bahasa jargon pada siswa mempunyai ciri khas tersendiri dalam berkomunikasi jika dibandingkan dengan bahasa yang dipergunakan masyarakat pada umumnya. Penggunaan bahasa jargon menghendaki adanya ucapan-ucapan kata-kata baru yang bersifat infomal.

Bentuk kata-kata baru itu diperoleh dengan cara menyamarkan arti yang dibentuk dengan susunan kata tersendiri. Makna-makna kata jargon menjadi tersamar dan ungkapan atau katanya jarang dimengerti oleh masyarakat atau remaja secara umum yang bukan remaja di dalam kelompok tersebut. Sedangkan tuturan yang bersifat informal karena dalam situasi-situasi percakapan sehari-sehari yang bersifat santai dan akrab antar anggota kelompok (Chaer dalam Agustina, 2010:14). Demikian halnya dengan penggunaan jargon yang digunakan oleh pemakainya, tentu memiliki karakteristik tersendiri sesuai dengan sifat pemakainya, saat jargon digunakan. Karakteristik bahasa jargon merupakan ciri khas dari suatu penggunaan variasi bahasa dalam suatu bidang tertentu atau pada saat variasi bahasa itu gunakan.

Secara umum karakteristik berasal dari kata karakter yang berarti watak. Karsakteristik adalah sifat khas yang tempat menampilkan diri dalam keadaan apapun dalam hal ini, bagaimanapun upaya untuk menutupi dan menyembunyikan watak, maka watak tersebut akan dapat ditemukan (Atmakusmali dalam Nurkhalid, 2008:18).

Dari penjelasan di atas, maka dapat dikatan bahwa karakteristik dari suatu bahasa jargon merupakan suatu ciri khas khusus dari suatu penggunaan variasi bahasa. Ciri 
CENDEKIA, Vol. 11, No. 1, April 2017

p ISSN: 1978 2098; e ISSN: 2407 8557

Http://cendekia.pusatbahasa.or.id; Email: cendekiaoslo@gmail.com

Center of Language and Culture Studies, Surakarta, Indonesia

Muhsan. 2017. Jargon dalam Interaksi Sosial Bahasa Sasak oleh Siswa MAN Lombok Barat. Cendekia, (2017), 11(1): 51 64.

tersebut terlihat dari sifat pengguna bahasa jargon itu sendiri saat dipraktikkan dalam melakukan suatu komunikasi.

Penggunaan jargon merupakan salah satu variasi bahasa yang bersifat khusus atau

khas. Artinya variasi bahasa tersebut dipakai oleh kalangan tertentu yang sangat terbatas, ada faktor-faktor tertentu yang menyebabkan terjadinya sifat bahasa yang demikian.

Penggunaan jargon bukan hanya ditentukan oleh faktor-faktor yang ada dalam bahasa tersebut yaitu faktor linguistik, melainkan juga ditentukann oleh faktor-faktor yang ada di luar bahasa tersebut yaitu faktor sosial dan situasional. Faktor sosial misalnya status sosial, tingkat pendidikan, umur, tingkat ekonomi, jenis kelamin, dan sebainya. Faktor situasional yaitu keadaan seseorang yang berbicara, dengan siapa, dengan bahasa apa, kapan, di mana, dan tujuan apa (Sugito, dalam Nurkhalid 2008:19)

Chaer dalam Agustina (1995:83) menyatakan bahwa Perbedaan-perbedaan variasi bahasa terjadi karena adanya faktor-faktor yang mempengaruhinya, antara lain.

1. Segi Penutur

2. Segi Pemakai

3. Segi Keformalan

4. Segi Sarana

Variasi bahasa yang digunakan tetap mempunyai umur sutu bahasa yaitu kesemestaan yang berarti bahwa bahasa sebagai ciptaan manusia dapat digunakan oleh siapapun, tanpa terhalang oleh lingkungan atau geografis dan kebudayaan yang berbeda (Cahyono, dalam Nurkhalid, 2008:19). Berdasarkan penjelasan diatas, maka dapat diketahui faktor-faktor timbulnya jargon dalam komunikasi, yaitu faktor sosial dan faktor situasional. Faktor-faktor yang mempengaruhi tersebut berhubungan dengan yang satu dan lainnya.

\section{METODE}

Jenis penelitian yang digunakan adalah kulitatif yang disajikan secara deskriptif. Penelitian kualitatif melibatkan pengukuran tingkatan suatu ciri tertentu. Untuk menemukan sesuatu dalam pengamatan, pengamat harus mengetahui apa yang menjadi ciri dari sesuatu itu (Moleong, 2000:2). Deskriptif kualitatif digunakan untuk menggambarkan atau memaparkan data-data yang diperoleh. Data-data yang diperoleh dideskripsikan dan dianalisis sesuai dengan bentuknya dan dari analisis tersebut akan diketahui bentuk, fungsi dan makna dari penggunaan jargon dalam interaksi sosial bahasa Sasak pada siswa Madrasah Aliyah Negeri Gerung.

Sebuah penelitian tidak terlepas dari populasi dan sampel. Populasi adalah wilayah generalisasi yang terdiri atas obyek/subyek yang mempunyai kualitas dan karakteristik tertentu yang ditetapkan oleh peneliti untuk dipelajari dan kemudian ditarik kesimpulan (Sugiyono, 2011:80). Populasi adalah keseluruhan subyek dan obyek penelitian (Arikunto, 2010:147). 
CENDEKIA, Vol. 11, No. 1, April 2017

p ISSN: 1978 2098; e ISSN: 2407 8557

Http://cendekia.pusatbahasa.or.id; Email: cendekiaoslo@gmail.com

Center of Language and Culture Studies, Surakarta, Indonesia

Muhsan. 2017. Jargon dalam Interaksi Sosial Bahasa Sasak oleh Siswa MAN Lombok Barat. Cendekia, (2017), 11(1): 51 64.

Berdasarkan kedua pendapat tersebut di atas, maka yang dimaksud dengan populasi adalah keseluruahan individu dan obyek yang akan diteliti yang mempunyai karakteristik tertentu dari semua obyek yang akan diteliti, namun juga populasi kurang dari 100 dianjurkkan semuanya dijadikan sampel (Arikunto, 2006:134). Maka yang menjadi populasi dalam penelitian ini adalah 50 orang siswa Madrasa Aliyah Negeri Gerung, Kabupaten Lombok Barat yang melakukan interaksi sosial dengan bahasa Sasak.

Sampel adalah sebagian atau wakil dari populasi yang diteliti (Arikunto, 2006:131). Jadi sampel adalah contoh yang diambil dari sebagian populasi penelitian yang dapat mewakili populasi. Walaupun yang diteliti adalah sampel, tetapi hasil penelitian atau kesimpulan penelitian berlaku untuk populasi atau kesimpulan penelitian digeneralisasikan terhadap populasi. Yang dimaksud menggeneralisasikan adalah mengangkat kesimpulan penelitian dari sampel sebagai sesuatu yang berlaku bagi populasi. Apabila sampelnya kurang dari 100, lebih baik diambil semua atau $100 \%$ sehingga penelitiannya merupakan penelitian populasi. Selajutnya, jika jumlah subyeknya lebih dari 100 dapat diambil sampelnya antara 10\%-15\% atau lebih.

Metode pengumlan data yang dimaksud adalah cara yang digunakan untuk mengumpulkan data dalam suatu penelitian dapat digunakan beberapa metode. Kegiatan pengumpulan data merupakan langkah yang sangat penting dalam penelitian, sebab data itu akan diolah pada langkah-langkah selanjutnya. Untuk mengumpulkan data dalam penelitian ini, menggunakan beberapa metode yaitu observasi. Dalam kamus besar bahasa indonesia (KBBI) menyatakan bahwa observasi adalah peninjauan secara cermat atau secara langsung ke suatu tempat (2014:793). Sedangkan menurut Arikunto (2002:232) mengemukakan bahwa observasi yang disebut juga pengamatan meliputi kegiatan pemusatan perhatian terhadap suatu obyek dengan menggunakan alat indra.

Adapun alasan peneliti menggunakan metode observasi ini adalah untuk mengetahui atau melihat secara langsung bagaimana bentuk penggunaan jargon dalam interaksi sosial bahasa Sasak, karakteristiknya dan faktor yang mempengaruhi jargon dalam interaksi sosial bahasa Sasak pada siswa Madrasah Aliyah Negeri Gerung, Kabupaten Lombok Barat. Untuk memaksimalkan hasil observasi, peneliti menggunakan beberapa alat bantu yang sesuai dengan kondisi lapangan. Metode kedua yaitu wawancara. Karena peneliti ingin memperoleh data yang lebih jelas dan lebih lengkap subyek yang dalam hal ini adalah siswa-siswi Madrasah Aliyah Negeri Gerung, kabupaten Lombok Barat, maka peneliti memilih metode wawancara sebagai salah satu metode pengumpulan data. Tehnik wawancara adalah dimana peneliti berhadapan muka secara langsung dengan subyek yang diteliti. Maka yang akan dilakukan oleh peneliti dalam peroses wawancara ini adalah mempersiapkan segala sesuatu atau informasi yang belum lengkap dari metode yang digunakan sebelumnya.

Teknik yang digunakan peneliti dalam menganalisa data sebagai berikut;

a. Trankripsi data. Penelitian ini berjenis kualitatif sehingga data yang ditrankripsi secara deskriptif. Data yang diperoleh dideskripsikan secara keseluruhannya kemudian ditrankripsikan dalam bentuk tabel sesuai dengan permasalahannya . 
CENDEKIA, Vol. 11, No. 1, April 2017

p ISSN: 1978 2098; e ISSN: 2407 8557

Http://cendekia.pusatbahasa.or.id; Email: cendekiaoslo@gmail.com

Center of Language and Culture Studies, Surakarta, Indonesia

Muhsan. 2017. Jargon dalam Interaksi Sosial Bahasa Sasak oleh Siswa MAN Lombok Barat. Cendekia, (2017), 11(1): 51 64.

b. Klasifikasi data. Kemudian diklasifikaikan berdasarkan kategori yang telah ditentukan. Klasifikasi dalam penelitian ini meliputi: (1) bentuk penggunaan jargon (2) karakter bahasa jargon, dan (3) faktor-faktor yang mempengaruhi timbulnya jargon.

c. Reduksi data. Teknik reduksi data yang digunakan dalam penelitian ini menggunakan metode observasi (pengamatan secara lansung). Yang dilakukan dengan mengamati data-data yang diperoleh kemudian diklasifikasikan menurut bidangnya masing-masing sehingga dapat ditarik kesimpulan sesuai dengan data yang kita butuhkan.

d. Interpretasi data. Data yang telah diklasifikasikan kemudian diinterpretasikan kedalam bentuk tabel sesuai dengan apa permasalahannya.

e. Penarikan kesimpulan. Dari data-data yang didapat, kita dapat simpulkan dalam tahap analisis ini mengungkapkan deskripsi bentuk penggunaan jargon dalam interaksi sosial bahasa Sasak pada siswa Madrasah Aliyah Negeri Gerung, Kabupaten Lombok Barat beserta maksud penggunaannya.

\section{HASIL DAN BAHASAN}

Bentuk dan makna Jargon

Di kalangan siswa MAN Gerung, terdapat dua bentuk jargon yang sering digunakan yaitu bentuk kata dan bentuk frasa. Dalam tabel 01. Terdapat data jargon dalam bentuk kata.

Tabel 01. Data dalam bentuk kata

\begin{tabular}{lll}
\hline No & Bentuk Kata & Makna \\
\hline $\mathbf{1}$ & Peleq & Mata sipit \\
$\mathbf{2}$ & Menembe & Lamban \\
$\mathbf{3}$ & Prongong & Lubang hidung besar \\
$\mathbf{4}$ & Nyeruntit & Banyak tingkah \\
$\mathbf{5}$ & Bloh/meler & Mata besar \\
$\mathbf{6}$ & Menyosoq & Sok \\
$\mathbf{7}$ & Joang & Besar telinga \\
$\mathbf{8}$ & Ngingil & Tertawa \\
$\mathbf{9}$ & Dagul & Kepalanya besar \\
$\mathbf{1 0}$ & Donyong & Kening menonjol \\
\hline
\end{tabular}

Berikut contoh-contoh penggunaan jargon bentuk kata dalam komunikasi oleh siswa MAN Gerung.

Contoh.

1) lemaq aru telalo jok sekolah aok peleq

Besok pagi kita pergi sekolah ya mata sipit

2) Mule siq menembe aziz jarian tuges nu

Aziz ini lamban sekali mengerjakan tugas itu

3) Apri lalo jok sekolah kance Iwan prongong. 
CENDEKIA, Vol. 11, No. 1, April 2017

p ISSN: 1978 2098; e ISSN: 2407 8557

Http://cendekia.pusatbahasa.or.id; Email: cendekiaoslo@gmail.com

Center of Language and Culture Studies, Surakarta, Indonesia

Muhsan. 2017. Jargon dalam Interaksi Sosial Bahasa Sasak oleh Siswa MAN Lombok Barat. Cendekia, (2017), 11(1): 51 64.

Apri pergi ke sekolah bersama Iwan besar lubang hidung.

Bentuk bahasa jargon yang berupa kata merupakan bentuk bahasa jargon yang jumlahnya paling sedikit pada data (1) [peleq] 'mata sipit' dan (2) [menembe 'lamban'] Maksud contoh kalimat pada data (1) seseorang teman yang mengajak temannya yang memiliki ciri-ciri bermata sipit pergi sekolah atau madrasah. Jargon ini muncul setelah mereka saling kenal antara siswa yang satu dengan yang lain Sedangkan pada data (2) adalah seseorang yang mengatakan kepada temannya kalau temannya itu malas atau lamban mengerjakan tugas, maksud data (3) adalah pada kalimat ketiga ini ahalah kalimat yang menjelaskan bahwa "Apri pergi kesekolah bersama Iwan yang memiliki ciri-ciri lubang hidung yang besar". Dengan menyebut nama ciri maka siswa dapat membedakan siswa yang bernama Iwan, karena siswa yang bernama Iwan ada dua orang.

Berikut data jargon berbentuk frasa.

Tabel 02. Data dalam bentuk frase

\begin{tabular}{lll}
\hline No & Bentuk Frase & Makna \\
\hline $\mathbf{1}$ & Tesorong isik mbok & Pembicaraan yang di dorong oleh napas \\
$\mathbf{2}$ & Tengkong kejemul & Seseorang yang sulit ditemukan \\
$\mathbf{3}$ & Betis ken odaq & Betis kecil dan panjang \\
$\mathbf{4}$ & Jerangkong irup & Badan yang kurus \\
$\mathbf{5}$ & Penyu kalo & Seseorang yang membuat kita sibuk \\
$\mathbf{6}$ & Paleng lenggen & Tertawa sampai mau pingsan \\
\hline
\end{tabular}

Data atau bentuk bahasa jargon yang berupa frase dalam penelitian ini adalah kata yang terdiri dari dua suku kata atau lebih yang tidak melebihi batas fungsi. Data yang berupa frasa ini sangat sedikit jumlahnya dan sangat jarang ditemukan dalam penelitian.

Contoh.

1. Eka ngeraos tesorong isik mbok

Eka berbicara didorong oleh napas.

2. Batur-batur Bime nu paleng lenggen gitaq Aziz tesuruq maju leq dalem kelas

Teman-teman Sekotong itu tertawa sampai mau pingsan lihat Aziz disuruh maju di dalam kelas

3. Andi teboyak jok sekolah kalah-kalahan te boyaq tengkong kejemul

Andi dicari ke sekolah sulit sekali ditemukan

Data (1) terdapat bentuk frase yaitu [tesorong isik mbok] yang artinya asal bicara tanpa dipikirkan akibat dari pembicaraannya itu. Kata [tesorong isik mbok] biasanya 
CENDEKIA, Vol. 11, No. 1, April 2017

p ISSN: 1978 2098; e ISSN: 2407 8557

Http://cendekia.pusatbahasa.or.id; Email: cendekiaoslo@gmail.com

Center of Language and Culture Studies, Surakarta, Indonesia

Muhsan. 2017. Jargon dalam Interaksi Sosial Bahasa Sasak oleh Siswa MAN Lombok Barat. Cendekia, (2017), 11(1): 51 64.

diucapkan oleh orang atau siswa yang sedikit sombong. Biasanya orang atau siswa seperti ini memiliki kemampuan yang minim. Maksud penggunaan data (2) temanteman siswa dari Bima itu menertawakan Aziz sampai mau pingsan karena disuruh maju oleh guru di dalam kelas dan data (3) adalah seseorang teman yang mencari Andi di sekolah sulit sekali ditemukan. Mencari Andi di sekolah sama artinya kita mencari jamur di musim panas. Ini dapat kita lihat dari kata [boyaq tengkong kejemul].

Data yang terdapat dalam fungsi jargon yang digunakan dalam interaksi sosial bahasa Sasak adalah sebagai berikut.

a. Untuk mempermudah pengucapan yang panjang dan berbelit

Tabel.04. Data pengucapan yang panjang dan berbelit

\begin{tabular}{lll}
\hline No & Kata/istilah jargon & Makna \\
\hline $\mathbf{1}$ & Nyerutit & Tidak bisa diam \\
$\mathbf{2}$ & Ngewer-ewer & Ikut-ikutan \\
$\mathbf{3}$ & Kecentet & Senyum tapi kelihatan giginya \\
$\mathbf{4}$ & Onseng rending & Marah berlebihan \\
$\mathbf{5}$ & Prongong & Lubang hidung besar \\
$\mathbf{6}$ & Pokoqn saqwus & Asal bicara \\
\hline
\end{tabular}

Fungsi jargon dapat dikelompokkan sebagai berikut

a) Fungsi dalam penggunaanya yaitu memudahkan bagi orang atau kelompok yang memahaminya, mempermudah keterangan yang panjang dan berbelit sehingga menjadi bahasa yang efektif dan efesien dalam komunitas tersebut.

Contoh.

1) Anita makaq saq nyerutit laloq leq dalem kelas oneq! Anita kenapa sih kamu banyak bicara tadi didalam kelas!

1) Andi side ny jaq pokoqme saq wus jawab pertanyaan oneq pas te diskusi nu!

Andi kamu ini asal bicara aja jawab pertanyaan pas kita diskusi tadi!

3) Prongong irongme Aziz

Aziz kebesarnya lubang hidungmu

Data (1) adalah merupakan fungsi dalam penggunaanya tujuannya untuk mempermudah pengucapan yang panjang. Maksud dari data (1) adalah untuk menyegarkan suasana yang sepi agar menjadi rame, dan data (2) adalah seseorang teman atau sahabat byang sengaja menggunakan kata istilah agar teman tidak marah. Maksud data (3) adalah seseorang teman yang mengejek temannya karena lubang hidungnya besar tetapi yang diejaek tidak marah karena sudah dianggap biasa. 
CENDEKIA, Vol. 11, No. 1, April 2017

p ISSN: 1978 2098; e ISSN: 2407 8557

Http://cendekia.pusatbahasa.or.id; Email: cendekiaoslo@gmail.com

Center of Language and Culture Studies, Surakarta, Indonesia

Muhsan. 2017. Jargon dalam Interaksi Sosial Bahasa Sasak oleh Siswa MAN Lombok Barat. Cendekia, (2017), 11(1): 51 64.

Tabel. 05. Data sebagai fungsi identitas.

\begin{tabular}{lll}
\hline No & Kata istilah (Jargon) & Arti \\
\hline $\mathbf{1}$ & Ngewer-ewer & Ikut-ikutan \\
$\mathbf{2}$ & Warang & Saudara \\
$\mathbf{3}$ & Kunsi & Saudara \\
$\mathbf{4}$ & Paleng lenggen & Tertawa berlebihan \\
$\mathbf{5}$ & Betis ken odaq & Betis yang kecil dan panjang \\
\hline
\end{tabular}

Dari data di atas dapat dilihat bahwa fungsi sebagai identitas adalah Kemampuan dalam menggunakan jargon akan mempengaruhi kreadibilitas dan kelayakan seseorang dalam kelompok karena mampu memahami ide dasar dalam kelompok tersebut. Selain itu jargon juga dapat meningkatkan image, citra, dan prestige, oleh karena itu, seseorang yang sering menggunakan jargon sesuai dengan tempat tinggal atau kelompok yang diikutinya seseorang tersebut akan semakin bangga dengan register yang digunakannya.

Contoh.

1) Bariyadin: Eko makaq saq menyosoq laloq jarin Eka nane muq te bedait la ndeq sapaq-sapaqte aneq

2) Bariyadin: Eko kenapa sih Eka itu nakal sekali soq jadinya sekarang kalo kita ketemu ndaq kita di tegur-tegur ya

3) Eko: aro ye mule ntan Eka leq laeq Den, ye ndeq nginiq rubah sifatne menyosoq muq nyerocos malik.

Eko: ya dia memang begitu caranya Eka dari dulu Den, dia ndaq bisa rubah sifatnya udah nakal, soq banyak bicara lagi.

Maksud data (1) adalah Bariyadin menceritakan kepada Eko kalau temennya siq Eka itu soq gaya di sekolah dan data (2) adalah merupakan kata yang menggugah semangat temannya yaitu Eko.

Data pada Tabel 06 menunjukkan bahwa fungsi kata untuk menghidupkan suasana yang sepi agar menjadi rame, seseorang kelompok atau mahasiswa Sasak sering menggunakan kata [kepitiq kepoah], kecentet dan seterusnya.

Contoh.

1. Dewiq: Laa oneq Ambar kepitik kepoah leq dalem kelas ngingil batur-baturnuq isiqme.

Dewiq: la tadi ya Ambar tidak bisa diam didalam kelas temanteman tertawa jadinya gara-gara kamu.

2. Bagus: makaq kedemen laloq gitamme Dewiq ariq muq kenyekeng kencentet

Kenapa saya senang sekali lihat adik Dewiq kalo lagi senyum. 
CENDEKIA, Vol. 11, No. 1, April 2017

p ISSN: 1978 2098; e ISSN: 2407 8557

Http://cendekia.pusatbahasa.or.id; Email: cendekiaoslo@gmail.com

Center of Language and Culture Studies, Surakarta, Indonesia

Muhsan. 2017. Jargon dalam Interaksi Sosial Bahasa Sasak oleh Siswa MAN Lombok Barat.

Cendekia, (2017), 11(1): 51 64.

Tabel.06. Data fungsi untuk menyegarkan suasana atau untuk mengangkrabkan temannya

\begin{tabular}{lll}
\hline No & Kata & Arti \\
\hline $\mathbf{1}$ & Kepitiq kepoah & Tidak bisa diam \\
\hline $\mathbf{2}$ & Kencentet & Saya \\
$\mathbf{3}$ & Pokoqn saq wus & Asal bicara \\
\hline $\mathbf{4}$ & Tengkong kejemul & $\begin{array}{l}\text { Seseorang yang sulit } \\
\text { ditemukan }\end{array}$ \\
\hline $\mathbf{5}$ & Belong kebango & Leher panjang \\
$\mathbf{6}$ & Jungaq & Kelihatan giginya \\
\hline $\mathbf{7}$ & Ngingil & Tertawa \\
\hline $\mathbf{8}$ & Lahop & Saudara \\
\hline $\mathbf{9}$ & Menao & Sok tau \\
\hline $\mathbf{1 0}$ & Menyeket & Sok pintar \\
\hline
\end{tabular}

Data (1) kata [kepitiq kepoah] yang artinya tidak bisa diam. Maksud dari data (1) adalah Dewik ini mengatakan kepada Ambar bahwa kalau Ambar ini tidak bisa diam di dalam kelas selalu mengajak temannya ribut, dan data (2) adalah seseorang teman yang senang melihat teman perempuannya kalo lagi tersenyum.

Data dalam makna atau isi jargon yang terdapat dalam interaksi sosial bahasa Sasak adalah sebagai berikut.

Tabel.07. Makna atau Isi Jargon.

\begin{tabular}{lll}
\hline No & Bentuk jargon & Makna \\
\hline $\mathbf{1}$ & Menyeket & Sok pintar \\
$\mathbf{2}$ & Memble & Pemalas \\
$\mathbf{3}$ & Ngewer-ewer & Ikut-ikutan \\
$\mathbf{4}$ & Oleng & Pusing \\
$\mathbf{5}$ & Kepitiq kepoah & Tidak bisa diam \\
$\mathbf{6}$ & Klebet & Mantap \\
$\mathbf{7}$ & Nyerocos & Keceplosan \\
$\mathbf{8}$ & Pokoqn saq batuk & Asal bicara \\
$\mathbf{9}$ & Menao & Sok pintar \\
$\mathbf{1 0}$ & Maraq kempilin & Kecil sekali \\
\hline
\end{tabular}


CENDEKIA, Vol. 11, No. 1, April 2017

p ISSN: 1978 2098; e ISSN: 2407 8557

Http://cendekia.pusatbahasa.or.id; Email: cendekiaoslo@gmail.com

Center of Language and Culture Studies, Surakarta, Indonesia

Muhsan. 2017. Jargon dalam Interaksi Sosial Bahasa Sasak oleh Siswa MAN Lombok Barat.

Cendekia, (2017), 11(1): 51 64.

Bentuk makna atau isi bahasa jargon dalam interaksi sosial bahasa Sasak berupa kata merupakan bentuk yang tidak mengalami perubahan atau pemendekan bentuk kata tersebut digunakan seperti aslinya. Bentuk kata yang digunakan berupa kata.

Contoh.

1. Arina makat saq menyosoq laloq leq sekolah yaq

Dia kenapa Arina ini sok sekali di sekolah ini

2. Kesendem jari baokme semetonke nane

Ketebalnya jenggot saudara sekarang

3. Bandi pokoqn saq batuk ngeraos leq julun kelas

Bandi asal bicara aja didepan kelas

Bentuk bahasa jargon yang berupa makna atau isi jargon adalah kata [menyosoq] yang artinya soq sedangkan kata sendem artinya tebal maksud data (1) adalah seseorang teman yang mengatai Arina kalau Arina itu soq di sekolah dan pada data (2) adalah seseorang teman yang mengatakan kepada temannya kalau jenggotnya panjang dan tebal. Dan maksud contoh pada data (3) adalah seseorang teman yang mengatai Bandi asal bicara saja di depan kelas.

Data atau bentuk bahasa jargon yang berupa frasa dalam penelitian ini adalah kata yang terdiri dari dua suku kata atau lebih yang tidak melebihi batas fungsi. Data yang berupa frasa ini sangat sedikit jumlahnya dan sangat jarang ditemukan dalam penelitian.

Contoh.

1. Mule menyanteq Apri leq batur-baturnu

Selalu ingin dilihat cantik Apri ini sama teman-teman itu

2. Nyerutit ambar namun leq dalem kelas jeq

Banyak bicara Ambar ini kalao didalam kelas

3. Bayu maraq kempilin siq gitaqme Icak

Bayu melihat Icak kecil sekali

Tabel 08. Data dalam bentuk frasa

\begin{tabular}{lll}
\hline No & Bentuk Frase & Makna \\
\hline $\mathbf{1}$ & Pokoqn saq batuk & Asal bicara \\
$\mathbf{2}$ & Tengkong kejemul & Seseorang yang sulit ditemukan \\
$\mathbf{3}$ & Betis ken odaq & Betis kecil dan panjang \\
$\mathbf{4}$ & Kepitiq kepoah & Tidak bias diam \\
$\mathbf{5}$ & Penyu kalo & Seseorang yang membuat kita sibuk \\
$\mathbf{6}$ & Maraq kempilin & Kecil sekali \\
$\mathbf{7}$ & Ngantos & Menunggu \\
$\mathbf{8}$ & Sendem & Tebal \\
$\mathbf{9}$ & Ngeremon & Bicara sendiri \\
$\mathbf{1 0}$ & Pineng ulu & Sakit kepala \\
\hline
\end{tabular}


CENDEKIA, Vol. 11, No. 1, April 2017

p ISSN: 1978 2098; e ISSN: 2407 8557

Http://cendekia.pusatbahasa.or.id; Email: cendekiaoslo@gmail.com

Center of Language and Culture Studies, Surakarta, Indonesia

Muhsan. 2017. Jargon dalam Interaksi Sosial Bahasa Sasak oleh Siswa MAN Lombok Barat.

Cendekia, (2017), 11(1): 51 64.

Data (1) terdapat bentuk frase, yaitu [mule menyanteq] Apri yang artinya Apri selalu cantik. Maksud penggunaan data (1) adalah seseorang teman yang mengatakan kalau Apri selalu ingin dilihat cantik sama teman-teman di kelas dan data (2) adalah seseorang teman yang mengatakan kepada temannya si Ambar ini banyak bicara di dalam kelas dan tidak bisa diam. Maksud data (3) adalah Bayu ini melihat temennya sik Icak kecil sekali.

Tabel.09 Data dalam bentuk kalimat

\begin{tabular}{|c|c|c|}
\hline No & Bentuk kalimat & Makna \\
\hline 1 & $\begin{array}{l}\text { Pokoqn saq wus Bandi leq julun } \\
\text { guru menao }\end{array}$ & $\begin{array}{l}\text { Asal bicara saja Bandi didepan guru } \\
\text { sok pintar }\end{array}$ \\
\hline 2 & $\begin{array}{l}\text { Bapak Salman teboyak kalah- } \\
\text { kalahan teboyak Tengkong } \\
\text { kejemul }\end{array}$ & $\begin{array}{l}\text { Bapak Salman dicari sulit sekali } \\
\text { ketemu }\end{array}$ \\
\hline 3 & Naen Vebi maraq betis ken odaq & KakinyaVebi kecil dan panjang \\
\hline 4 & $\begin{array}{l}\text { Perane Eka maraq Jerangkong } \\
\text { irup }\end{array}$ & Badannya Eka kurussekali \\
\hline 5 & $\begin{array}{l}\text { Aziz ne jaqpenyu kalo jamaq } \\
\text { taoq ite nulis ne }\end{array}$ & $\begin{array}{l}\text { Aziz ini membuat kita sibuk aja tau } \\
\text { kita lagi menulis }\end{array}$ \\
\hline 6 & $\begin{array}{l}\text { Paleng lenggen gitaq batur- } \\
\text { batur nu teuruq maju siq pak } \\
\text { Salman }\end{array}$ & $\begin{array}{l}\text { Tertawa sampai mau pingsan melihat } \\
\text { teman-teman itu di suruh maju sama } \\
\text { pak Salman }\end{array}$ \\
\hline
\end{tabular}

Data atau bentuk bahasa jargon yang berupa kalimat dalam penelitian ini adalah kata yang terdiri dari kalimat. Yang menjadi syarat bagi suatu kalimat adalah kesempurnaan dalam tanggapan yang harus dinyatakan dalam kelengkapan bentuk.

Contoh.

1) Mbe laiq warang tie?

Mau kemana saudara?

2) ompreng jamaq batur- baturnu bejanji bedait leq Bundaran Gerung burung

Saya kesal sama teman-teman ini dia sepakat ketemu di Bundaran Gerung ndak mereka datang

Data (1) adalah merupakan kalimat tanya [mbe laiq warang] yang artinya mau kemana saudara. Maksud dari data (1) seseorang teman yang bertanya kepada temannya dan data (2) adalah merupakan kalimat yang menyatakan tempat. Maksud dari data (2) seseorang teman yang kesel atau jengkel sama temannya kalo dia tidak ditemui di suatu tempat yaitu Bundaran Gerung. 
CENDEKIA, Vol. 11, No. 1, April 2017

p ISSN: 1978 2098; e ISSN: 2407 8557

Http://cendekia.pusatbahasa.or.id; Email: cendekiaoslo@gmail.com

Center of Language and Culture Studies, Surakarta, Indonesia

Muhsan. 2017. Jargon dalam Interaksi Sosial Bahasa Sasak oleh Siswa MAN Lombok Barat.

Cendekia, (2017), 11(1): 51 64.

\section{SIMPULAN}

Isi jargon dalam interaksi sosial bahasa Sasak pada siswa Madrasah Aliyah Negeri Gerung, Kabupaten Lombok Barat mempunyai bentuk makna atau isi tersebut antara lain: bentuk kata, frasa dan kalimat. Maksud makna dari penggunaan jargon adalah isi yang berupa kata misalnya kata [memble] artinya pemalas. Hasil penelitian yang diperoleh, penulis simpulkan sebagai berikut:

1) Untuk mempermudah pengucapannya yang panjang dan berbelit. Maksudnya adalah apabila terdapat kata yang panjang dan berbelit maka digunakanlah kata istilah tersebut misalnya kata pokoqn saq wus artinya bicara asal-asalan

2) Fungsi yang kedua yaitu sebagai identitas maksudnya adalah apabila suatu kelompok menggunakan kata istilah maka suatu kelompok tersebut akan semakin bangga dengan register yang digunakannya itu.

3) Fungsi yang ketiga yaitu untuk menyegarkan suasana. Maksudnya adalah apabila disuatu kelompok atau komunitas yang sering melakukan perkumpulan sering terjadi suana yang sepi dan hening maka digunakanlah kata istilah atau jargon untuk menghidupkan suana tersebut misalnya kata tengkong kejemul yang artinya seseorang yang sulit ditemukan.

\section{DAFTAR PUSTAKA}

Aslinda dan Syafyahya Leni. 2007. Pengantar Sosiolinguistik. Bandung: Rifika Aditama. Alwasilah, Chaedar. 1985. Sosiologi Bahasa. Angkasa: Bandung.

Arikunto. 2002. Metodologi Penelitian. Penerbit PT. Renika Cipta.

Chaer, Abdul dan Leoni, Agustina.2004. Sosiolinguistik: Perkenalan Awal. Jakarta: Renika Cipta.

Caer, Abdul dan Agustina, Leonie. 2010. Sosiolinguistik: Perkenalan Awal. Renika Cipta: Jakarta

Cristina. 2008. Wikipedia. Org/Wiki/Wikipedia: Tehnical Termsand

DefenitionsKhomariah Lis. 2011 .Jargon Yang Digunakan Komunitas Banci

Salon Di Kota Padang, sumatra Barat (Tinjauan sosiolingistik). (Skripsi)

Universitas Andalas: Padang

Kridalakasana, Harimurti, 1974. Fungsi Bahasa dan Sikap Bahasa. plores: Nusa Indah

Microsoft Encarta. 2009. Legelese Defenitions Language.

Moleong, Lexy J. 2000. Metodologi Penelitian kualitatif. Bandung: PT. Remaja Rosdakarya

Nurkholid. 2008. Metode Analisis Data. Renika Cipta: Jakarta

Soeparno. 2003. Dasar-dasar Linguistik. Renika Cipta: Jakarta

Sugiyono. 2011. Metode Penelitian Kuantitatif, Kualitatif dan R\&D. Penerbit Alfabeta. Bandung

Wardhaugh. 2006. An Introduction to sosiolinguistik. PT. Renika Cipta. Bandung 